\title{
TRABALHO E EDUCAÇÃO: AMBIENTE, RELAÇÕES DE TRABALHO E SAÚDE DOS PROFISSIONAIS (PROFESSORES) DA EDUCAÇÃO DE ALTAMIRA.
}

\section{WORK AND EDUCATION: ENVIRONMENT, WORKING RELATIONS AND TEACHERS' HEALTH IN ALTAMIRA.}

Rozinaldo Ribeiro da Silva ${ }^{1}$

Verusa Almeida da Silva²

\section{RESUMO}

O artigo tem como objetivo identificar os fatores implícitos nas instituições municipais de ensino de Altamira, que colaboram para o surgimento e/ou agravamento do mal estar docente e analisar como o ambiente e as relações de trabalho promovem o desequilíbrio na saúde desses profissionais. No primeiro momento foi realizada a pesquisa bibliográfica utilizando como referências as contribuições de Marx (1988), Codo (1993), lamamoto (2006), Gramsci (1995), Silva (2005), Tardif (2009). Na busca de resposta ao problema, para fins de organização optou-se por realizar, juntamente com a pesquisa bibliográfica, a pesquisa de campo, que ocorreu na SEMEC, ALTAPREV, SINTEPP e CAPS, nestes órgãos foram adquiridos documentações formais para análise da problemática em questão e em três Escolas Municipais de Ensino Fundamental foram aplicados questionários aos professores. Os dados adquiridos na pesquisa empírica possibilitaram observar que a grande maioria dos profissionais da educação afastados e/ou reabilitados no período da pesquisa são professores (as); todos os docentes entrevistados relataram algum tipo de mal estar relacionado ao contexto "ambiente e relações de trabalho". Assim, foi possível concluir que tanto o ambiente, quanto as relações de trabalho implicam diretamente na saúde docente.

PALAVRAS-CHAVE: Trabalho - Ambiente de trabalho - Relações de trabalho - Saúde docente. 


\section{ABSTRACT}

This paper aims at identifying the factors implicit in the municipal educational institutions from Altamira that contribute to the emergence and/or worsening of discomfort of teachers. It also analyses how the teaching environment and working relations promote the imbalance of these professionals health. At first, a research was conducted by using bibliographical references as the contributions by Marx (1988), Codo (1993), lamamoto (2006), Gramsci (1995), Silva (2005), and Tardif (2009). Looking for an answer to this problem (and with organizational purposes) we chose to implement a field research as well, which took place in SEMEC, ALTAPREV, SINTEPP and CAPS. At these institutions, formal documentation for analysis of the problems were acquired, and at three Municipal Elementary Schools teachers answered to some questionnaires. Through the data acquired it was possible to observe that the majority of education professionals in remote and/or after rehab (by the time of this study) are teachers; all teachers who were interviewed reported some type of discomfort related to context, "environment and working relations ". Therefore, we concluded that both the environment and working relations directly interfere in teachers' health.

KEYWORDS: Work - Working environment - Working relations - teachers' health.

\section{INTRODUÇÃO}

Neste trabalho discutimos alguns questionamentos a cerca das implicações do ambiente de trabalho e das relações de trabalho na saúde dos professores da rede municipal de ensino do município de Altamira-Pará. No primeiro momento foi realizada a pesquisa bibliográfica utilizando como referências as contribuições de Marx (1988), Codo (1993), lamamoto (2006), Gramsci (1995), Silva (2005) e Tardif (2009).

O segundo momento deste trabalho foi realizado através de pesquisa empírica. Ou seja, durante dois meses; abril e maio de 2010 tivemos a oportunidade de entrevistar dez professoras, dentre estas sete são docentes da EMEF Carlos Leocárpio Soares, duas da EMEF Nair Lemos e uma da EMEF Otacílio Lino, todas as escolas citadas encontram-se 
localizadas na zona urbana do município de Altamira. A essas professoras foi aplicado um questionário a fim de obter dados relevantes do processo de trabalho das mesmas. $O$ questionário foi dividido em três partes. A $1^{\circ}$ trata de questões relacionadas ao ambiente de trabalho e é formado por doze perguntas; a 20 parte discorre a cerca das relações de trabalho e é composta por treze perguntas, e a $3^{\circ}$ e última etapa ressalta as implicações das relações de trabalho na saúde dos profissionais docentes e é formado por dez perguntas.

A fim de adquirir dados que pudessem consolidar a pesquisa bibliográfica, mas, sobretudo confirmar os dados obtidos nas entrevistas com os professores, foi realizada uma pesquisa na SEMEC - Secretaria Municipal de Educação, Cultura e Desporto. No órgão citado obtivemos a quantidade de profissionais da educação afastados por licença médica e/ou readaptados durante os meses de abril e maio de 2010.

\section{A SITUAÇÃO DOS TRABALHADORES EM EDUCAÇÃO EM ALTAMIRA: $O$ TRABALHO NA ESCOLA, A VIDA E A A SAÚDE.}

Para com lamamoto (2006), o trabalho é uma atividade pragmática e de realização; seu produto é objetivação, simultaneamente, das mãos e do cérebro, das aptidões corporais e intelectuais do homem (MARKUS, 1974b, apud, lamamoto, 2006). Assim podemos salientar que o professor utiliza sua força de trabalho, sua capacidade e potencial de trabalho para produzir seu valor de uso o "conhecimento" através do processo de ensino-aprendizagem. A criação de novas necessidades, por meio do trabalho, se traduz na criação do homem com ricas e múltiplas faculdades, com sentimentos profundos, dotado de curiosidade científica, aspirações religiosas, estéticas, do conhecimento prático cotidiano. O trabalho (e a linguagem, enquanto exterioriza os resultados da produção intelectual), objetivação de forças essenciais humanas (faculdades e necessidades), cria, pois, a possibilidade permanente de evolução humana: a própria história.

Para Gramsci (1995), todos os homens são intelectuais, mas nem todos os homens desempenham na sociedade a função de intelectuais. Assim, este autor ressalta que a escola é o instrumento para elaborar os intelectuais de diversos níveis. Portanto, quando se distingue entre intelectuais e não-intelectuais faz-se referência, na realidade, 
tão somente à imediata função social da categoria profissional dos intelectuais, isto é, leva-se em conta a direção sobre a qual incide o peso maior da atividade profissional especifica, se na elaboração intelectual ou se no esforço muscular-nervoso. Isto significa que, se pode falar de intelectuais é possível falar de não-intelectuais. Entretanto, a própria relação entre o esforço de elaboração intelectual-cerebral e o esforço muscular-nervoso não é sempre igual; por isso, existem graus de intelectualidade específica.

Portanto, a primeira ação metodológica para aprofundar o conhecimento acerca da situação de trabalho dos trabalhadores em educação foi procurar conversar diretamente com vários professores. As primeiras informações obtidas nos levaram a tomar consciência das reais condições do ambiente de trabalho nas escolas públicas municipais de Altamira, das condições físicas das salas, cadeiras, quadro-branco, quadro-negro, o tamanho das salas, as condições de ventilação, a higiene, a quantidade de alunos por sala, as condições de segurança dentro e fora da sala de aula.

Segundo Marx (1988), a utilização da força de trabalho é o próprio trabalho. O comprador da força de trabalho consome-a, fazendo seu vendedor trabalhar. Este, ao trabalhar, torna-se realmente no que antes era apenas potencialmente: força de trabalho em ação, trabalhador. Para o trabalho reaparecer em mercadorias, tem de ser empregado em valores-de-uso, em coisas que sirvam para satisfazer necessidades de qualquer natureza. O processo de trabalho acontece da interação do homem com a natureza.

No processo de trabalho na escola, podemos considerar as idéias de Marx, compreendendo que o profissional da educação, embora não tenha um contato direto com a natureza, a utiliza de uma forma indireta, subscrita, pois assim como em várias outras áreas do trabalho, utilizam-se produtos dos processos de outros trabalhos para produzir seus valores-de-uso: o conhecimento. As provas, os testes, os concursos e a produção de mercadorias novas ou a melhoria das já existentes servem de demonstração de como a educação se apresenta como instrumento de produção de valores-de-uso.

Para Tardif (2009), a escola possui características organizacionais e sociais que influenciam diretamente no trabalho docente. Por se tratar de um trabalho, ela não é apenas espaço físico, mas também um espaço sociocultural e político e que define como o trabalho do professor é repartido, planejado, renumerado e visto por outros. A sócioorganização das escolas implica na codificação e burocratização do trabalho docente. São as regras da administração que regem as relações de trabalho dentro das escolas. 
Assim, a primeira ação metodológica para aprofundar o conhecimento acerca da situação de trabalho dos trabalhadores em educação foi procurar conversar diretamente com vários professores. As primeiras informações obtidas nos levaram a tomar consciência das reais condições do ambiente de trabalho nas escolas públicas municipais de Altamira, das condições físicas das salas, cadeiras, quadro-branco, quadro-negro, o tamanho das salas, as condições de ventilação, a higiene, a quantidade de alunos por sala, as condições de segurança dentro e fora da sala de aula.

\section{O AMBIENTE DE TRABALHO NAS INSTITUIÇÕES DE ENSINO PÚBLICO.}

Durante dois meses, pesquisamos com os profissionais da educação e com SINTEP (Sindicato dos Trabalhadores da Educação do Pará) a fim de obter dados reais e concretos para análise das condições físicas do ambiente escolar. A pesquisa foi realizada com dez professores da rede municipal de ensino. Dentre os profissionais entrevistados todos estavam em plena atividade de ensino.

Aplicamos um questionário, composto por doze perguntas de estruturação discursiva, acerca do tema ambiente de trabalho, conforme se verifica a seguir:

1. A estrutura física das salas de aula é adequada para um bom desempenho profissional? A maior parte dos professores respondeu que não. Alguns relataram que as salas são pequenas para quantidade de alunos, outros enfatizaram o piso, que não é adequado para as crianças e ainda oferecem riscos. Outro fator que também foi citado como relevante é a questão da pintura, as salas passam por um longo período sem reforma, ficando assim com a estrutura completamente comprometida.

2. As cadeiras - sala de aula e sala dos professores - são confortáveis? Nesta questão, unanimemente a resposta foi não. Os docentes relatam que as cadeiras são extremamente desconfortáveis e que culmina significativamente o aparecimento de dores na região lombar.

3. As salas de aula são arejadas? Não, foi a resposta da maior parte dos docentes. Alguns relatam que as salas são quentes e sem ventilação. Porém, é interessante ressaltar que outros destacam que, na escola onde trabalham, as salas são arejadas e possuem iluminação adequada. 
4. O espaço das salas de aula é satisfatório para desenvolver uma aula de qualidade?A maioria respondeu que sim, que embora haja fatores negativos, os mesmos não interferem relevantemente na qualidade da aula ministrada. Entretanto, alguns professores relataram que, as dificuldades encontradas no espaço da sala de aula provocam, sim, uma diminuição na qualidade do processo de ensinoaprendizagem.

5. As salas são barulhentas? A maioria respondeu que sim e, relatam que as escolas nas quais lecionam estão localizadas próximas a ruas com movimento acentuado de veículos. Segundo respostas dos docentes, esse fator causa incômodo auditivo; dispersa a atenção dos alunos e do professor e ainda força o professor a elevar o tom da voz, provocando assim, desconforto e dores nas cordas vocais.

6. O acesso as escolas é bom? Esta pergunta é referente à localização da escola. A maioria dos profissionais respondeu que sim, que a escola na qual lecionam está localizada em uma rua trafegável e de acesso facilitado com razoável pavimentação.

7. Qual o seu meio de transporte? (Casa/Escola - trabalho). Dentre os profissionais questionados, a maioria vai para o trabalho a pé ou usa bicicleta/moto. Poucos utilizam carro próprio como meio de transporte casa/trabalho.

8. A escola esta localizada em área de risco? Sim. De acordo com as entrevista foi possível notificar que todas as escolas nas quais os entrevistados trabalham possuem algum fator de risco. Algumas por estarem localizadas em ruas e avenidas com alto fluxo automobilístico, o que causa uma grande preocupação com relação a acidentes, outras em bairros de classe média baixa, com notável índice de violência, o que promove insegurança, tanto para os profissionais da educação quanto para os alunos.

9. Existe segurança no interior da escola? E exteriormente? Nessa questão a maioria das respostas foi afirmativa, salvo alguns casos isolados de violência e agressão verbal. Porém, é relevante citar que alguns docentes não se sentem seguros no ambiente escolar e encontram uma desmedida insegurança em relação à segurança exterior.

10. Existe alimentação para o corpo docente da escola? Resposta unânime: sim. A merenda escolar, servida para a classe discente, também é servida para os professores. 
11. Qual a média de alunos por classe? Tomando uma média geral dos professores entrevistados, podemos citar que a maioria possui cerca de 30 alunos por classe. No entanto, alguns chegam a ter 40 alunos por sala.

12. Quanto à higiene da escola, ela existe em todo o ambiente escolar? Também foi possível verificar unanimidade uma resposta afirmativa. Os docentes descrevem as escolas como sendo um ambiente bem higienizado. Interessante ressaltar que essa higienização ocorre no limite, com o mínimo necessário. Ou seja, para os professores as escolas encontram-se no limite entre a limpeza e a sujeira.

Desta primeira parte do questionário aplicado aos docentes é possível observar diversos problemas, principalmente em relação à estrutura física das escolas, que acarretam danos à saúde no profissional docente. Dentre os problemas mais recorrentes citados pelos professores, temos o uso do quadro-negro - o pó de giz é extremamente prejudicial à pele, à garganta e compromete também a visão e pulmões. Ainda é muito comum encontrarmos o quadro de giz na maioria das escolas públicas do município.

A estrutura elétrica também é outro fator relatado. O ventilador de teto, que pouco ventila, geralmente fica localizado por baixo das lâmpadas que oferecem iluminação precária. Esse tipo de estrutura provoca uma sombra giratória que em longo prazo deixa efeitos colaterais irreversíveis na visão dos professores e, conseqüentemente, provoca danos à visão dos alunos também.

Este trabalho não trata de encontrarmos a etiqueta adequada para classificarmos 0 professor doente, nem de fazermos apologia de uma nova síndrome e respectivo tratamento, quase sempre medicamentoso. Pelo contrário, devemos assumir a miopia de nossos instrumentos de leitura diante da aceleração vertiginosa que marca a velocidade da época e, assim, escaparmos das lentes que medicalizam a vida. É nesta perspectiva que olharemos para o sofrimento docente, problematizando os múltiplos vetores que concorrem para a sua produção. Que forças concorrem e se afirmam na fabricação do professor estressado, desvitalizado, despotencializado, enfim, do professor adoecido.

Há dois séculos Karl Marx já dizia que as épocas econômicas são distintas não pelo como é feito a mais-valia, mas sim, pelo ambiente onde ocorre o processo de trabalho (MARX, 1988). O ambiente precisa estar em condições favoráveis para que o resultado do processo de trabalho seja um produto de qualificação. Só assim, com qualidade, o trabalho consegue atingir seu propósito, que é suprir necessidades do homem. 


\section{RELAÇÕES SOCIOECONÔMICAS E POLÍTICAS NO AMBIENTE ESCOLAR}

O trabalho docente é indispensável na área educacional e apresenta várias especificidades, visto que é um trabalho cujo produto não se separa do ato de produção. É um trabalho traduzido por conhecimentos, idéias, conceitos, valores, atitudes, símbolos que interagem através das relações pedagógicas historicamente determinadas que se formam entre os homens.

Para Tardif (2009), a escola moderna reproduz, no plano de sua organização interna, um grande número de características tiradas do mundo usineiro e militar do Estado. Ela trata uma grande massa de indivíduos de acordo com padrões uniformes por um longo período de tempo, para reproduzir resultados semelhantes; submete esses indivíduos (professores e alunos) a regras impessoais, gerais, abstratas, fixadas por leis e regulamentos; estabelece um sistema de vigilância, de punições e recompensas que não se limitam aos "conteúdos da aprendizagem", mas incluem também suas formas e modos: atitudes e posturas corporais, modos de se exprimir, de sentar-se etc. Dentro da escola, o trabalho escolar - ou seja, o conjunto de tarefas cumpridas pelos agentes escolares, inclusive os alunos - é ele próprio, padronizado, dividido, planificado e controlado. Os professores encontram-se integrados a uma estrutura celular do trabalho, sobre a qual se sobrepõe uma burocracia impositiva.

Pode-se dizer que a escola e o ensino têm sido historicamente invadidos e continuam ainda a sê-lo, por modelos de gestão e de execução do trabalho oriundos diretamente do contexto industrial e de outras organizações econômicas hegemônicas. O que chamamos "condições de trabalho" dos professores corresponde a variáveis que permitem caracterizar certas dimensões quantitativas do ensino: o tempo de trabalho diário, semanal, anual, o número de horas de presença obrigatória em classe, o número de alunos por classe, o salário dos professores, entre outras.

Tendo em vista o exposto, a seguir, passaremos à segunda parte do questionário aplicado aos professores da rede pública do município de Altamira, o qual enfatiza as relações socioeconômicas e políticas no interior das escolas.

Esta parte do questionário, composta por treze questões, e tem por objetivo analisar sistematicamente se e o quanto estas relações implicam na saúde do trabalhador docente, conforme se observa a seguir. 
1. Você é efetivo ou contratado? Dentre os profissionais entrevistados, a maioria é efetiva.

2. Qual o valor da hora-aula? Para os que possuem nível médio, o valor da hora aula é $R \$ 5,82$ (cinco reais e oitenta e dois centavos), enquanto que para os que possuem nível superior o valor é de, aproximadamente, $R \$ 7,90$ (sete reais e noventa centavos). Dentre os entrevistados, 06 (seis) têm curso superior e 04 (quatro) o estão cursando.

3. Qual sua carga horária total diária e mensal? Tendo em vista que a maior parte dos entrevistados possui cargo efetivo, a maioria possui, assim, 8 (oito) horas diárias de atividades escolares em sala de aula.

4. Você possui tempo disponível para planejamento de aula?Por unanimidade, a resposta foi negativa. Todos os professores relataram que a falta de tempo para o planejamento escolar, no ambiente escolar, acarreta uma sobrecarga de trabalho no ambiente familiar.

5. Qual sua média, em horas, de descanso diário? Tendo em vista que a maioria das pessoas entrevistadas é de mulheres, grande parte é casada e tem filhos. $O$ horário de descanso fica extremamente diminuído e precisa ser bem distribuído entre esposo, filhos, tarefas de casa e ainda as tarefas extra-escolares. Sendo assim, o tempo de descanso, propriamente dito, só acontece no momento de dormir.

6. Você possui um tempo descriminado para o convívio familiar e lazer? A maior parte respondeu que sim. Porém, todos se queixam que esse tempo é insuficiente e que gostariam de passar mais tempo com a família e de acompanhar mais de perto 0 desenvolvimento dos filhos. Ou seja, o tempo para o convívio familiar ficou comprometido, pois, em casa, os professores têm de planejar aula, corrigir provas e trabalhos, dentre outras atribuições discriminadas na questão 5 acima.

7. Como você avalia a sua relação professor-professor; professordireção; professor aluno; professor-comunidade? A maior parte dos professores descreve uma relação razoável, no limite do bom convívio. Salvo algumas exceções, que sempre ocorrem, de um modo geral há uma relação estável no ambiente escolar. 
8. Você já foi transferido da escola em que leciona - lecionava - por motivos políticos? Não. Essa foi à resposta da maioria das pessoas entrevistadas. Porém, é relevante ressaltar que houve relatos de professores que foram transferidos da escola na qual trabalhavam por motivos de oposição partidária, onde sofreram represálias e constrangimento moral.

9. Você já foi punido com redução de carga horária em conseqüência de escolhas políticas? Entre os entrevistados ninguém sofreu esse tipo de punição.

10. Você já sofreu assédio moral ou sexual no ambiente escolar? Em média metade dos professores respondeu que sim, que em algum momento já sofreu algum tipo de assedio. Alguns relatam ter sofrido assédio por parte de alunos, outros por parte de professores e, ainda há os assediados pela direção, coordenação, vigilantes etc.

11. Você já se sentiu coagido profissionalmente no período eleitoral? Como aconteceu? A minoria respondeu que não, com ressalvas a alguns profissionais que relatam que se sentiram coagidos nesse período por medo de perder carga horária, alguns de serem transferidos para zona rural, e outros, ainda, descreveram o medo que sentiram em perder o cargo ocupado.

12. Você sofre algum tipo de pressão a fim de que sejam atingidas determinadas metas? Sim foi a resposta unânime dos entrevistados. Todos descreveram que esse tipo de problema é muito comum. Existe uma pressão considerável por parte da coordenação para que esses profissionais atinjam metas pré-estabelecidas pelas secretarias de educação do município. São metas de freqüência escolar dos alunos, metas de aprovação dos alunos etc.

13. Você se sente um profissional realizado na área da educação? A maioria respondeu que sim, que embora a profissão apresente diversas problemáticas, nos mais diversos níveis, esses profissionais sentem-se realizados e gostam do que fazem. Porém almejam um ambiente físico adequado para realização das atividades e gostariam de receber renumeração digna para a classe e, principalmente, desejam que o docente seja mais valorizado, enquanto profissional. 
Tendo em vista os relatos dos professores sobre as relações de trabalho e, seguindo os estudos realizados - anteriormente - das implicações dessas relações na saúde docente, apontamos alguns problemas que foram diversas vezes citados pela classe em questão. De acordo com os professores entrevistados, a carga horária do docente produz um nível de estresse e cansaço acentuado, tendo em vista que eles não gozam de tempo para o planejamento curricular no ambiente escolar. Essa atividade acaba sendo feita em casa no momento de um suposto "descanso". A carga horária também indisponibiliza os profissionais de participar de outras atividades ligadas à educação.

Torna-se comum, no ambiente escolar, a valorização das técnicas de gerenciamento, transformando o aluno em consumidor de ensino e o professor em funcionário treinado $\mathrm{e}$ competente. Assim, a escola vai aos poucos preparando mãode-obra com as novas exigências do mercado de trabalho e tratando o ensino público como mercadoria, trazendo no bojo o tecnicismo que reduz os problemas sociais a questões administrativas, esvaziando os campos sociais e político do debate educacional, transformando os problemas da educação em problemas do mercado e de técnicas de gerenciamento. No entanto o profissional docente não está, de modo algum, longe dessa problemática vivida por todos os ramos profissionais. Podemos dizer, até, que o corpo docente está relevantemente mais exposto a diversos problemas do que várias outras profissões.

Silva (2005) ressalta que na economia política, a categoria trabalho é apresentada, apenas, como produção de mercadorias, ou como emprego. Nessas condições, o trabalho é degradante para o homem. Ao discutir a relação homemtrabalho, Marx (cf. MANACORDA, 1991, apud Silva) emprega, às vezes, também o termo "trabalho" como "vida produtiva" ou "atividade humana". Porém, em geral, tal emprego é feito, exatamente, para especificar que essa atividade livre e consciente - nas condições acima ressaltadas - impede a satisfação de necessidades humanas, pois implica a exploração do homem pelo homem. Assim, para Marx, o trabalho seria destruidor e desmoralizador para a classe trabalhadora. Como a educação burguesa se volta ao atendimento das necessidades desse tipo de trabalho, também podemos considerá-la como negativa para o homem e, portanto, desmoralizadora.

Podemos afirmar que séculos se passaram, mas as implicações negativas das condições de trabalho e suas implicações na saúde do trabalhador continuam indubitavelmente relevantes. O trabalho deixa sua marca registrada em cada indivíduo, e nos professores não é diferente. Os profissionais entrevistados relatam constantes dores nos membros 
inferiores devido ao longo tempo que ficam em pé; dores nos membros superiores, em conseqüência da má estrutura do quadro que, além de ser alto, os professores o utilizam por períodos longos de tempo, provocando assim dores constantes nos braços e mãos. Descrevem ainda constantes dores de cabeça, em decorrência do barulho em sala de sala, barulhos externos, agitação dos alunos, conseqüência de uma noite mal dormida etc.

Atualmente o papel do professor extrapolou a mediação do processo de conhecimento do aluno, o que era comumente esperado. Ampliou-se a missão do profissional para além da sala de aula a fim de garantir uma articulação entre a escola e a comunidade. O professor, além de ensinar, deve participar da gestão e do planejamento escolares, o que significa uma dedicação mais ampla, a qual se estende às famílias e à comunidade.

Verificamos que as atribuições aos docentes têm aumentado imensuravelmente. Porém, as condições físicas das escolas e a estrutura hierárquica do ambiente escolar dificultam bastante o desenvolvimento do trabalho docente. As políticas públicas voltadas ao campo educacional não incluem e nem promovem a diminuição do impacto das relações de trabalho e das condições de trabalho na saúde do professor. Essa problemática acarreta uma bola de neve, pois são diversos profissionais da educação, debilitados, estressados, deprimidos. Assim, esse problema gera muitos atestados médicos e diversas e repetidas readaptações.

Para Tardif (2009), o ensino é um trabalho burocratizado cuja execução é regulamentada, mas que também repousa sobre a iniciativa dos atores e que requer de sua parte certa autonomia. Esse trabalho é definido por regras administrativas e depende, igualmente, ou mais ainda, da atividade responsável e autônoma dos professores e de seu envolvimento com a profissão.

A segunda categoria refere-se ao processo de ensino-aprendizagem, que engloba 0 planejamento a longo, médio e curto prazo (ano, período e dia) da matéria, sua superação em seqüências hierárquicas, as transformações da matéria, sua separação em seqüências hierárquicas, as transformações da matéria conforme o planejamento e a aprendizagem que consideram as preocupações afetivas dos alunos, sua motivação, seu nível, sua heterogeneidade etc. 


\section{O TRABALHO E SUAS IMPLICAÇÕES NA SAÚDE DOCENTE}

Trataremos, então, da terceira parte do questionário aplicado aos professores. Esta parte trata as implicações das relações de trabalho na saúde dos profissionais da educação é composta por dez questões, abaixo relacionadas:

1. Você já foi afastado do trabalho por problemas de saúde, decorrentes da sua profissão (professor)? Sim foi à resposta da maior parte dos entrevistados. Eles relatam o afastamento pelos mais variados motivos. Uns ressaltam a hierarquia na gestão escolar como a principal causa dos problemas de saúde como o estresse, a depressão, a baixa estima.

Outros relatam as condições físicas das escolas como as cadeiras, que não são, de modo algum, confortáveis e geralmente promovem dores na coluna vertebral, o giz, que causa irritação nas amídalas, nos olhos, manchas na pele, problemas pulmonares etc., o excesso de alunos nas salas, que exige do professor atenção redobrada e isso provoca dores de cabeça, estresse, dor na garganta. A carga horária de trabalho é um dos itens mais recorrentes, pois, segundo os entrevistados, provoca cansaço físico, dores musculares, desequilíbrio emocional por, às vezes, não conseguir conciliar trabalho, filhos, esposo, fazer exercícios físicos, ir a uma festa, fazer compras, planejar aulas, ir ao salão, jogar bola, sair com os amigos, passear com a família, fazer uma viagem.

2. Por quanto tempo? O tempo de afastamento varia bastante de professor para professor e pode ser de um a seis meses.

3. Houve reincidência? A maioria relata que sim, que sempre ocorre reincidência devido à persistência dos problemas acima relacionados.

4. Houve reabilitação? Sim. Na maior parte dos casos ocorreu reabilitação/ readaptação.

5. Qual seu principal problema de saúde? Os problemas de saúde relatados pelos docentes são diversos. Porém, ainda é interessante ressaltar que todos relatam mais de um problema, ou seja, são um conjunto de dores nas mais diversas formas. Dentre eles podemos destacar dores nos membros superiores e inferiores, dores de cabeça, rinite, alergia, cansaço físico e mental, depressão, vertigem, desequilíbrio emocional, fadiga, dores na garganta, dores musculares, insônia, baixa auto-estima, problemas gástricos e, principalmente, estresse. 
6. Qual foi o fator que desencadeou esse problema? A maioria dos entrevistados relata mais de um fator para os problemas de saúde apresentados, ou seja, é um conjunto de fatores, de ações e reações que desencadeiam as doenças relacionadas. Dentre esses fatores destacamos a carga horária excessiva; as estruturas físicas das escolas; a hierarquia na gestão escolar; super lotação nas salas de aula; falta de recursos financeiros para a realização de atividades extraclasse; a pressão para que as metas pré-estabelecidas sejam cumpridas e, em alguns casos, a falta de segurança no interior e exteriormente a escola, outro fator que também foi ressaltado pelos docentes a respeito da lei de inclusão dos portadores de necessidades especiais, segundo os mesmos não existe suporte físico, didático tão pouco qualificação profissional para trabalhar com esses alunos.

Isso implica em mais uma sobrecarga de trabalho.

7. O que precisa mudar no ambiente escolar a fim de evitar outros problemas, reincidências e até mesmo problemas futuros? Dentre as resposta obtidas, a maior parte acredita que a reforma escolar, a renumeração salarial adequada, a redução da carga horária, uma reformulação no modo de gestão escolar, a revisão das leis de integração dos portadores de deficiências, tudo isso certamente promoveria uma melhora significante no que concerne o bem estar social e a saúde do profissional docente.

8. Você já sofreu acidente no trabalho? Os entrevistados não relataram qualquer tipo de acidente.

9. Você sente insônia? A maioria dos docentes descreveu crises de insônia, devido à fadiga e cansaço físico e mental.

10. Você tem algum vício? Ele é decorrente da profissão? Entre os profissionais docentes entrevistados nenhum relatou possuir qualquer tipo de vício decorrente da profissão

De acordo com os resultados das pesquisas realizadas nos meses de abril e maio de 2010 e, segundo dados oficiais da Secretaria municipal de educação (SEMEC), no mês de abril, 31 (trinta e uma) pessoas da área de educação deram entrada com a licença-saúde. Dentre estes, 02 (dois) são professores e 16 (dezesseis) professoras, ou seja, soma um total de 18 profissionais docentes fora da sala de aula por motivos de doença. Quanto à 
readaptação, 09 (nove) profissionais da educação tiveram readaptação provisória. Não houve readaptação definitiva durante o mês em questão. Porém, dentre os 09 readaptados, 06 (seis) são professoras. Não houve professor readaptado.

No mês de maio 22 pessoas da área educacional obtiveram licençasaúde: 02 (dois) professores e 15 (quinze) professoras. Houve 10 (dez) readaptações, 01 (um) professor e 09 (nove) professoras. Os afastamentos variam em média de 15 dias a 02 meses de licença e as readaptações variam de 01 mês a 06 meses. Contudo, podemos concluir que em abril a maior parte dos profissionais afastados e das readaptados são professores.

Em maio, a maioria dos afastamentos e das readaptações foi de profissionais do corpo docente. Nos dois meses citados, tanto nas licenças quanto nas readaptações, podemos notar que a maioria é composta por professoras. Isto porque o corpo docente do município de Altamira é formado por uma maioria de profissionais do sexo feminino; e trata-se de um grupo que está mais exposto a problemas familiares e sociais.

Outros problemas que ocupam lugar de destaque entre os mais citados pelos entrevistados são: irritações e alergias especialmente na pele e nas vias respiratórias provocadas pelo pó de giz; calos nas cordas vocais; sobrecargas musculares e para 0 sistema circulatório provocadas por excessiva permanência em posturas incômodas (muito tempo em pé ou em assentos não ergonômicos); trabalho que exige muita atenção com o público; conflitos nas relações pessoais motivados ou acentuados pela múltipla convivência (idem para aumento de possibilidade de contrair doenças infecciosas, parasitárias etc.); autoritarismo burocrático; excesso de responsabilidade para o tempo e os meios de que dispõe, obrigando-se o professor a realizar mal o seu próprio trabalho; insegurança cotidiana típica de serviço sobre o qual não se podem estabelecer normas precisas e quantidades de ações que resultem, necessariamente, no objetivo desejado, e conseqüente dificuldade de avaliação quanto aos resultados alcançados. Essa análise, assim como um dos antídotos para mudar esse quadro, é compartilhada pelos pesquisadores que tratam do tema.

O que se observa é que os docentes precisam ter um espaço de escuta institucional. É preciso democratizar as relações nas instituições. Pode-se substituir o giz e ter tratamento acústico, que são medidas importantes. Mas isso não dá conta do problema. O cerne é a organização do trabalho.

Segundo Tardif (2009), as variações da tarefa dos professores são difíceis de avaliar, considerando que elas incluem muitas atividades informais e sofrem muita influencia de 
diferentes fatores associado ao sexo, ao status empregatício, ao tamanho das escolas, à região, aos alunos, ao tamanho da turma etc. A definição das tarefas docentes é suscetível de interpretações e de negociações em função dos atores locais, das tradições próprias dos estabelecimentos, das relações de poder entre as diretorias e os professores etc.

Há indícios de que a organização do trabalho docente pode ser um dos fatores que adoece e agrava a doença dos docentes. O atendimento médico dos docentes é precário, demorado e não atende a todas as necessidades deles. Há professores que não vão ao médico porque podem descobrir o que é melhor não saber. Afinal de contas, toda consulta médica resulta numa receita. Há na escola, professores hipertensos, diabéticos com problemas nas cordas vocais, estressados, obesos. Essas são algumas das doenças que tem sintomas visíveis. Outras, também graves e com sintomas nem sempre visíveis, são a depressão, o desânimo, o mal-estar que muitos sentem e que não são tratados porque se considera que esta é uma profissão tão bonita e nobre que só isto já é motivo suficiente para manter a auto-estima elevada.

Há poucos cuidados preventivos com a saúde e os poucos que há não são levados a sério pela maioria dos docentes. Nas observações que fiz constatei que foram raras as semanas que não havia um ou mais professores afastados por problemas de saúde. Havia professores com doenças comuns que curam mais rápido. Por outro lado, havia outros com quadros depressivos, que tinham crises na escola, agredindo colegas, alunos, funcionários, além de ter crises de choro, entre outras reações.

Nesse sentido Silva (2005, p. 73) afirma:

[...] Se for exatamente verdade, como se demonstrou, que o trabalho é, nas condições históricas dadas, destruição do homem, criação de um poder estranho ao homem e que o domina, como pode o trabalho libertar o homem se é a causa da sua servidão? A resposta aos questionamentos consiste em dizer que é, de fato, adotando o trabalho como princípio fundamental da formação humana (como processo educativo) que se podem subverter as condições sociais e libertar o homem das limitações impostas pela atualidade. A relação ensino-trabalho, entendidos como elementos não separados, é fundamental para a emancipação humana. Mas se o trabalho, a atividade vital, é a manifestação do homem, a sua relação voluntária, consciente e universal com a natureza, o dever antropológico com a natureza etc. como é possível que, mesmo quando dadas todas as condições para a sua plena manifestação, seu reino permaneça o da 'necessidade' e não o da liberdade? 
O autor ainda ressalta que para que os trabalhadores em educação acompanhem essa evolução rumo ao reino da liberdade é necessário que assumam a necessidade de considerar a educação a partir do seu trabalho diário na escola. E se faz presente, em nossa opinião, a necessidade da escola e, também, dos educadores, de lutar pela redução do trabalho em seu lado negativo, ampliando os conhecimentos necessários à emancipação social e, posteriormente, à formação unilateral.

A escola não estaria isenta destas contradições sendo possível, inclusive, que, por meio dela, seja transmitida aos trabalhadores a teorialtécnica que Ihes permitam a compreensão da sua real situação e uma leitura crítica da sociedade capitalista, fomentando, assim, a luta de classes no interior da escola. O marxismo compreende a educação como algo que transcende os muros da escola formal e indicam como elementos educadores dos trabalhadores, as associações, sindicatos e partidos políticos de classe.

O trabalho tem caráter "antinômico", ou seja, possui expressões negativas e positivas, é condição para a formação histórica do homem. Assim, as intenções educativas de tornar evidentes as contradições do capitalismo, para possibilitar uma formação emancipacionista, devem tê-lo como base. $\mathrm{O}$ marxismo entende que o trabalho é 0 princípio educativo fundamental dos homens e, por isso, os trabalhadores devem impor a escola do trabalho, fundamentada na formação teórico-técnica, isto é, educação profissional e educação tradicional unidas.

Assim, podemos concluir que o ambiente de trabalho, assim como as relações de trabalho comprometem a saúde dos professores, entretanto, notadamente pode salientar que 0 mal estar docente causa um efeito desastroso na qualidade de ensino. Desta forma todos tem a perder os professores que perdem parcialmente sua saúde; a direção e coordenação escolar que precisam providenciar professores substitutos; as secretárias de educação, pois é um gasto dobrado nos cofres públicos, os alunos são prejudicados tendo em vista que o rendimento do professor doente fica reduzido, ou então quando este é substituído existe um período de adaptação do professor substituto com os mesmos.

Portanto, se queremos não somente sobreviver no trabalho e sim fazer do trabalho uma fonte de saúde e realização cabe a cada um de nós, mas do que chorar e lamentar iniciar um processo de mudança pessoal e institucional, com propostas construtivas e participativas. Administrar a própria saúde e buscar aliados para iniciar um movimento que leve a construção de espaços mais saudáveis no contexto de trabalho. 


\section{REFERÊNCIAS BIBLIOGRÁFICAS}

BRASIL, Lei de Diretrizes e Bases da Educação Nacional. Lei no 9.394/96. Estabelece as diretrizes e bases da educação nacional. Diário Oficial da República Federativa do Brasil. Brasília, DF, 23 de dezembro de 1996.

GRAMSCI, Antonio. Os intelectuais e a organização da cultura. 9 ed. Rio de Janeiro: Civilização Brasileira, 1995.

IAMAMOTO, Maria V. Trabalho e indivíduo social: um estudo sobre a condição operária na agroindústria canavieira paulista. 2 ed. São Paulo: Cortez, 2006.

MARX, Karl. O Capital. São Paulo: Nova Cultural. caps. V e XIII. (Col. Os Economistas 1988).

SILVA, Rozinaldo R. Os limites e virtudes do projeto político pedagógico da Universidade Federal do Pará. Belém: UFPA/Centro de Educação, 2005.

TARDIF, Maurice. O trabalho docente: elementos para uma teoria da docência como profissão de interações humanas. 5 ed. Petrópolis, RJ: Vozes, 2009.

1 Pedagogo, Mestre em Educação pela UFPA. Professor da Faculdade de Educação da UFPA. rozinaldo@ufpa.br

2 Graduada em Licenciatura Plena em Pedagogia pela Universidade Federal do Pará - Campus de Altamira. Professora da Escola Municipal de Ensino Fundamental Carlos Leocárpio Soares. verusaalmeida 8@hotmail.com

ARTIGO RECEBIDO EM 30.09.2010

ARTIGO APROVADO EM 19.10.2010 